\title{
The Process of Regionalization and Its Effect on Complex Environmental Regimes
}

\author{
Evgenia Gordeeva ${ }^{1}$ \\ ${ }^{1}$ Chair of Forest Policy and Forest Resource Economics, TU Dresden, Germany \\ Correspondence: Dr. phil. Evgenia Gordeeva, Chair of Forest Policy and Forest Resource Economics, TU Dresden, \\ Pienner Straße 8, 01737 Tharandt, Germany. E-mail: evgenia.gordeeva@tu-dresden.de
}

Received: March 21, 2021

doi:10.5539/jsd.v14n3p164
Accepted: April 30, $2021 \quad$ Online Published: April 30, 2021

URL: https://doi.org/10.5539/jsd.v14n3p164

\begin{abstract}
I believe that the phenomenon of regionalization that currently gains weight as a characteristic of the international system bears a great potential for increasing the effectiveness of complex international environmental regimes. Constituting a sub-level within the international system, macro-regions create a bridge between the anarchy of the international system and the order of the state, by doing so, allowing for a certain amount of intra-regional cooperation to emerge and facilitating inter-regional coordination. The corresponding fragmentation of complex environmental regimes into sub-regimes consisting of groups of states sharing certain characteristics and interests can be expected to contribute to an increase in their effectiveness.
\end{abstract}

Keywords: international environmental regimes, regionalization, regime fragmentation

\section{Introduction}

Since the beginning of 1970 s, the natural environment has been subject to international discussion. Many environmental regimes ensued, yet, the majority of them remained of fairly limited effectiveness (thereafter to be understood as the expected compliance with the regime's norms and regulations by its participants), especially on the global dimension. Having studied the reasons behind this reality, two central variables determining the failure or success of a global environmental regime became evident - the complexity of the issue they are designed to address and the national interest of its participants. With this in mind, the following work summarizes the major findings of the research I conducted so far and presents a possible solution to the identified problem.

\section{Theory and Methods}

Constituting elements of the international system, international environmental regimes are subjected to its structure defining the framework in which they operate and conditional upon the units of which they consist. The necessity to study both the structure and the units of the international system in order to understand it in its entirety is a research design in line with the systems approach to the study of the international-political system introduced by Kenneth Waltz in 1979.

Following the tenets of the rationalist theories of international relations, we assume states to be the units of the international system. Among the key properties of the state there are power and interests, while the system structure can be characterized by such elements as polarity and the dominant type of economic relations (Wendt, 1987). The interests of a state are defined by its historically and geographically determined properties, such as the availability or absence of certain resources, relative military power, the level of sociocultural and economic development, existing alliances etc. The international structure, in turn, is "defined, first, by the ordering principle of the system, in our case anarchy, and second, by the distribution of capabilities [or power] across units" (Waltz, 1990, p.29).

In an anarchical system, thus, in the absence of an overarching authority, the states become competing units that act on the basis of rational choice. In respect of this rationality states are like-units, which yet differ in their capabilities, thus, in their relative power (Waltz, 1979; Waltz, 1990). International regimes are instruments established by states on the basis of cooperation with the aim to promote international order (Little, 2011). Yet, under the given systemic framework, international cooperation between states is "constrained by the dominating logic of security competition, which no amount of cooperation can eliminate" (Mearsheimer, (1994-95), p. 9). Therefore, the resulting negotiated outcome defining the regime will reflect the power relations between states that are party to the respective regime. 
Unlike in high political regimes, though, within international environmental regimes - as in most other low political regimes - we will find that it is not necessarily the external relative power of an actor that matters most, but its bargaining power. This was exemplified, among others, by David Humphreys who identified the countries with the biggest portions of forest resources and strongest forest-related economies as the central powers within the international dialogue system on forests under the aegis of the United Nations (UN) (Humphreys, 2005). Stephen Krasner came to the same conclusion by showing that Third World states were able to successfully assert their position with regard to the allocation of the electromagnetic spectrum within the global telecommunications regime due to the bargaining power they obtained by the ability to interfere with broadcasts from other states (Krasner, 1983). Consequently, the bargaining power of an actor within an environmental regime would be predominantly determined by either the availability of the resource which is to be protected (e.g. forests, water, a landscape or a certain natural object etc.) or the industries involved with the resource/process which is being addressed by the regime (e.g. DuPont, Allied Chemical, Hoechst, ICI or Atochem in the case of the Ozone depletion regime (Falkner, 2009)).

\section{Results}

Among the global environmental regimes that constitute the subject to this analysis, those ones that have proven to be effective had two things in common - they were design to tackle so-called "tame" (Grundmann, 2018, p. 438) or "benign" (Wettestad, 2011, p. 321) problems, while the goals pursued by the regimes did not contradict the national interest of its key participants. Benign problems are straightforward, thus, they address one specific issue that can be solved with clear and evidently effective methods at comparatively low cost. Among the most illustrative examples of this type of "simple" regimes are the Ozone depletion regime and the Antarctic Treaty System.

Ineffective regimes, on the other hand, are mostly characterized by what Wettestad, 2001, has referred to as "malignant" or Grundmann, 2018, as "wicked" problems. The wickedness of the problems lies in the fact that there is no easy solution to them - the sources of the problem are multiple and the solutions are often accompanied by scientific uncertainties and great costs, both in absolute and in relative terms. Applied on a global scale, the complexity of the issue itself is met with the complexity and heterogeneity of the international system that consists of a solid number of different actors each with its unique economic, political and social characteristics determined by geographical location and history. Those differences result in varying interests and economic-political capabilities of the actors. So, for example, global warming will not equally (and not necessarily negatively) affect all countries, while the idea of enhanced global forest conservation will be met with strikingly different positions depending on the actor asked. Adding the fact that the international system is currently organized as a balance of power system in which the great powers need to agree upon an issue in order for it to become a global regime and to coordinate their actions in order for it to function, the picture becomes complete. Indeed, as evidence suggests, complex environmental regimes eventually end up being either dead letter regimes (Note 1), e.g. the 1992 Rio Conference, or effectively fail as was the case with the attempted global climate change regime that failed at Kyoto first and then practically dissolved into regional sub-regimes, such as the European Union (EU) with its current Green Deal.

\section{Discussion}

Thus, while simple regimes are not part of the effectiveness problem, complex environmental regimes require an approach different from the one applied today. In this regard, I believe that the process of regionalization that currently gains weight as a characteristic of the international system might be interesting to look at. Situated between the level of the structure and that of the unit, macro-regions create a sub-level within the international system that allows to bridge between the sharp differentiation of cooperation- and coordination-based functional patterns of international regimes (Note 2), by doing so, to mitigate the dilemma between the anarchy of the international system and the (unfulfilled) requirement to act globally faced by ineffective international regimes.

Within a macro-region, the major obstacles to cooperation - the problem of relative gains and the problem of cheating (Baylis, 2011, pp. 235-236) - can be overcome to different extents depending on the level of integration provided within the region. The level of intra-regional integration depends on the strength of the ties that bind together the participants of a macro-region and are constituted by different combinations of shared cultural, political and economic interests a minimum amount of which is required for a geopolitical region to be formed. Those shared interests provide the basis for the emergence of mechanisms by means of which intra-regional cooperation can be achieved: enhanced information sharing and mutual control; and, most importantly, the element of order that starts to emerge when a certain level of political integration has been achieved. This element of order can be exercised by a core state or an authority acting in its stead - such as the Commission in the case of the 


\section{European Union.}

Through these mechanisms, intra-regional cooperation becomes possible allowing the participants to shift their attention from the relative gains towards the absolute gains within the inner-regional space. However, the fairly high level of economic-political integration that is required for the element of order to emerge within a macroregion imposes a limitation upon the applicability of this criterion of intra-regional cooperation. In fact, the only currently existent macro-region with a sufficient level of integration for the element of order to dominate over anarchy is the European Union. Yet, in less integrated macro-regions the degree of anarchy can still be expected to be lower than outside of the region which is due to the availability of a common interest that decreases the rationale of cheating with regard to the issue that constitutes the common interest as well as due to the possibility of enhanced information sharing and mutual control that is provided within a region.

In fact, evidence for the emergence of regional groupings within complex environmental regimes is already provided within the international system. As was shown on the example of the climate change regime, an interest group-building took place within the regime after it failed on the global scale with the result of even one fullfledged sub-regime developing within the EU (the European Green Deal). A similar observation can be made on the global forest regime, which failed to be institutionalized in a global forest convention (Humphreys, 2005; 2006), yet established itself as a fragmented mosaic of sub-regimes building an international forest regime construct (Pirlot, 2018).

Considering the current trends within the international system, its further regionalization seems probable. In light of this observation and the anticipated advantages a region-based approach to complex environmental problems might bring, studying the phenomenon of intra-regional integration and the effect it has on complex environmental regimes is a promising and well-timed task. Ideally, the imagined resulting framework for complex environmental regimes will contain an umbrella treaty specifying the scope of the regime and defining its norms, perhaps also establishing a corresponding institution and developing mutual control mechanisms, while each sub-regime will set its own concrete rules and obligations.

\section{Conclusion}

This work sought to inquire into the problem of the low effectiveness of complex environmental regimes and to elaborate on possible solutions. The analysis revealed two variables common for successful environmental regimes - low complexity and no contradictions with the national interest of its key participants (determined by bargaining power). Following thereout, the major problem behind complex environmental regimes was concluded to be the high economic and political cost of the associated measures as well as a great heterogeneity of involved interests represented by the regime participants.

A possible solution to this problem was found to be the process of regionalization that currently characterizes the international system. Building a sub-level between the unit and structure, macro-regions create a bridge between the anarchy of the international system and the order of the state. By doing so, they allow for a certain amount of intra-regional cooperation to emerge and facilitate inter-regional coordination. Both these effects can be expected to contribute to an increase in the overall effectiveness of a global environmental regime.

\section{References}

Baylis, J. (2011). International and Global Security. In Baylis, J., Smith, S., \& Owens, P. (Eds.), The Globalization of World Politics: An Introduction to International Relations (5th ed.). Oxford: Oxford University Press.

Falkner, R. (2009). Business Power and Conflict in International Environmental Politics. Palgrave Macmillan. https://doi.org/10.1057/9780230277892

Grundmann, R. (2018). Ozone and climate governance: An implausible path dependence. Comptes Rendus Geoscience, 350, 435-441. https://doi.org/10.1016/j.crte.2018.07.008

Humphreys, D. (2005). The Elusive Quest for a Global Forests Convention. RECIEL, 14(1). https://doi.org/10.1111/j.1467-9388.2005.00418.x

Humphreys, D. (2006). Logjam - Deforestation and the Crisis of Global Forest Governance. London: Earthscan.

Krasner, S. D. (1983). International Regimes. Cornell Univ. Press.

Lamy, S. (2011). Contemporary Mainstream Approaches: Neo-Realism and Neo-Liberalism; chpt. 7. In Baylis, J., Smith, S., \& Owens, P. (Eds.), The Globalization of World Politics: An Introduction to International Relations (5th ed.). Oxford: Oxford University Press.

Levy, M. A., Young, O. R., \& Zürn, M. (1995). The study of International Regimes. European Journal of 
International Relations, 1, 267-330. https://doi.org/10.1177/1354066195001003001

Little, R. (2011). International Regimes, chpt. 18. In Baylis, J., Smith, S., \& Owens, P. (Eds.), The Globalization of World Politics: An Introduction to International Relations (5th ed.). Oxford: Oxford University Press.

Mearsheimer, J. J. (1994-95). The False Promise of International Institutions. International Security, 19(3), 5-49. https://doi.org/10.2307/2539078

Pirlot, P. (2018). Fragmented Forest Policy: Asset or Concern? In Farcy, C. et al. (Eds.), Forestry in the Midst of Global Changes. Tailor \& Francis Group. https://doi.org/10.1201/b21912-20

Waltz, K. N. (1979). Theory of International Politics. McGraw Hill, New York.

Waltz, K. N. (1990). Realist Thought and Neorealist Theory. Journal of International Affairs, 44, 1.

Wendt, A. (1987). The Agent-Structure Problem in International Relations Theory. International Organization, 41(3), 335-370. https://doi.org/10.1017/S002081830002751X

Wettestad, J. (2001). Designing Effective Environmental Regimes: The Conditional Keys. Global Governance, 7(3), 317-341. https://doi.org/10.1163/19426720-00703008

\section{Notes}

Note 1. Using the classification suggested by Levy et al. 1995.

Note 2. See neo-neo debate, e.g. summary by Lamy 2011 \& Little 2011.

\section{Copyrights}

Copyright for this article is retained by the author(s), with first publication rights granted to the journal.

This is an open-access article distributed under the terms and conditions of the Creative Commons Attribution license (http://creativecommons.org/licenses/by/4.0/). 